\title{
ESTÉTICA DA EXPERIÊNCIA DE EDUCAR CONTRA O CONSERVADORISMO
}

\author{
Janete Magalhães Carvalho \\ Universidade Federal do Espírito Santo - UFES
}

\begin{abstract}
Resumo
Este artigo busca, por uma estética da experiência de educar e trabalhando com imagens, problematizar o conservadorismo político em suas implicações para a educação no Brasil atual. Entende o conservadorismo como uma força reativa, em acordo com uma postura individualista favorável ao "ideário colonial-capitalista” (Rolnik, 2016). Considera os cotidianos escolares como campos micropolíticos, atravessados pelo plano de organização das macropolíticas, como espaços-tempos que, pelos encontros dos corpos como coletivos, podem potencializar abertura para fissuras no status quo. Pesquisa, associando à problematização textual, imagens capturadas na Internet em site de humor político (charges) e estabelece, em encontros grupais, redes de conversações. Conclui que, nas dobras entre imagens-textos-conversações, os agentes fizeram problematizações e quebraram alguns clichês, como também foram capturados por imagensmoral, já que as ideias veiculadas pelas imagens participam de histórias e de memórias que as precedem. São vivas e, assim, não se constituem como figuras, pois envolvem também um mundo que se mostrou, nesse caso, como o das aprendizagens e do coletivo.
\end{abstract}

Palavras-chave: Conservadorismo. Estética. Experiência de educar. Micropolítica. Cotidianos escolares.

\begin{abstract}
It seeks for an aesthetics of the experience of educating and, working with images, problematizing political conservatism in its implications for education in Brazil today. It understands conservatism as a reactive force, in accordance with an individualist stance favorable to the "colonial-capitalist idea" (Rolnik, 2016). It considers the schools daily lifes as micropolitical fields, crossed by the macropolitical organization plan, as spaces-times that, by the meeting of the bodies as collective, can potentiate opening for cracks in the status quo. It researchs associating textual problematization with images captured on the Internet on a political humor site (cartoons) and establishing, in groups meetings, conversations networks. It concludes that, in the folds between images-texts-conversations, the agents made problems and broked some cliches, as well as were captured by moral-images, since the ideas conveyed by the images participate in stories and memories that precede them. They are alive and thus do not constitute themselves as figures, as they also involve a world that has shown itself, in this case, as that of learning and collective.
\end{abstract}

Key words: Conservatism. Aesthetics. Experience of educating. Micropolitics. Schools daily lifes.

ISSN 1645-1384 (online) www.curriculosemfronteiras.org 


\section{Introdução}

O artigo objetiva conceituar o conservadorismo político em suas implicações para as práticas discursivas em educação no Brasil atual, entendendo que, nos cotidianos escolares, como espaços micropolíticos ativos ou reativos, em seus diferentes níveis e graus, o uso de uma estética da experiência de educar pode potencializar a produção de problematizações necessárias à criação de acontecimentos coletivos contrários às forças “colonial-capitalísticas”.

Desse modo, entendemos os cotidianos escolares como campos micropolíticos, atravessados pelo plano de organização das macropolíticas, mas com potencial de reversão do poder imposto. Isso por se constituírem como campos heterogêneos, múltiplos, que se expressam por linhas de forças diversas, em meio às quais professores e alunos, envoltos em agenciamentos de ideias, devem buscar novos traços menos dogmatizados para suas aprendizagens.

Entramos, então, no campo do sensível, que nos força a pensar em outras maneiras, mais criativas, mais singulares, de movimentar o pensamento, ou seja, com imagens, buscar forçar o movimento do pensamento.

Como as imagens nos convocam a pensar?

Primeiro: porque toda imagem se associa a outras imagens visíveis/exteriores e mentais, portanto a outras memórias. Assim, toda imagem (um desenho, uma fotografia, uma pintura, um filme, uma poesia, um conto etc.) nos fornece algo para pensar; segundo: toda imagem é portadora de um pensamento, isto é, veicula pensamentos tanto de quem produziu a imagem como daqueles que compartilham essas imagens. "Toda imagem é uma memória de memórias, um grande jardim de arquivos declaradamente vivos” (Samain, 2012, p. 23); terceiro: toda imagem é independente de nós, pois toda imagem porta um conjunto de dados signícos e associa-se a outras imagens formando uma "forma que pensa" num fluxo de forças virtuais e atuais.

Segundo Samain (2012, p. 21), “[...] as imagens não são bolas de sinuca”, visto que não se deslocam somente quando impactadas, empurradas. São coisas vivas que se constituem como as borboletas, as ondas do mar... Assim, partimos da concepção de que, nos processos de aprendizagem, as imagens forçam o pensamento a se movimentar. Vivem e nos fazem viver, pois "a imagem é pensante” e, sem chegar a ser um sujeito, as imagens são mais que um objeto, pois não são pessoais; são vivas e partícipes de um sistema de pensamento. "A imagem, ao fazer parte integrante de um sistema no qual circula pensamento, ela participa desse pensamento, mas, sobremaneira, participa de um circuito de pensamentos” (Samain, 2012, p. 31-32).

As imagens também são formas do tempo, efêmeras, evanescentes, sempre de passagem no tempo, num fluxo de realidade que as faz jorrar em dois movimentos: de dentro para fora e de fora para dentro.

Didi-Huberman (2013) vê a imagem como uma vivência, uma sobrevivência e mais: uma supervivência que atravessa o tempo histórico e se nutre de um tempo anacrônico, visto que as ideias veiculadas pelas imagens são possíveis porque participam de histórias 
e de memórias que as precedem, das quais se alimentam antes de renascer um dia. Toda imagem pertence a um tempo profundo, quase imemorial, portanto é impossível considerar a imagem pelo que nos mostra, mas, precisamente, naquilo que esconde.

Assim, consideramos necessário desenvolver, nas pesquisas com os cotidianos escolares, uma estética dos encontros, nos quais os alunos e professores, por meio das imagens cinematográficas, pictóricas, fotográficas, literárias, possam pensar as escolas e a educação para além dos clichês, pois acreditamos, como Deleuze (1988), que o interessante é ver e perceber o imperceptível e pensar o impensável.

Nesse sentido, a pesquisa usou, como disparador de redes de conversações estabelecidas em quatro encontros, no primeiro semestre de 2019, com licenciandos cursando o último ano do Curso de Pedagogia ${ }^{1}$ de uma IES privada, uma síntese, formulada pela Confederação Nacional dos Trabalhadores em Educação (CNTE), dos principais pontos da política para o setor educação nos meses iniciais do governo Bolsonaro, em suas implicações para a educação brasileira e, em particular, para a profissionalidade docente, destacando, assim: a) a proposta de reforma da Previdência altamente prejudicial para os mais pobres e para o magistério e trabalhadores/as rurais; b) os sucessivos cortes nas políticas educacionais (ensino superior e educação básica) e a ameaça de acabar com a vinculação constitucional que assegura recursos para a educação (Fundeb e outras políticas); c) o patrulhamento ideológico nas universidades e a ofensiva da Lei da Mordaça (Escola sem Partido); d) a perseguição ao pensamento crítico com enxugamento de verbas para os Cursos de Filosofia e Sociologia nas universidades; e) o viés privatista e sectário que fomenta as políticas de vouchers e a educação domiciliar; f) a agressão à gestão democrática e à autonomia das escolas por meio da militarização escolar; g) a inoperância inescrupulosa do Ministério da Educação que afeta a qualidade do atendimento público nas escolas, institutos federais e universidades; h) a revogação de inúmeros Conselhos de acompanhamento social, impondo retrocessos à gestão democrática estatal; i) o ataque à organização sindical (MP 873) com o objetivo de enfraquecer a luta social contra esses desmandos praticados em pouco mais de sete meses (CNTE, 2019).

Nesse aporte, as conversações foram tomadas para além do processo de individualização, ou seja, concebidas como agenciamentos em redes de conversações (Carvalho, 2019) que potencializam acontecimentos inscritos em modos coletivos, buscando superar a dicotomia indivíduo e sociedade. Coletivo não como totalização, mas como ativação da sensibilidade das forças que transbordam a cartografia vigente em seu entorno e exigem um trabalho de criação que redesenhe seus contornos.

O estudo exprimiu uma proposta voltada para a estética da experiência educativa nos cotidianos escolares e, nesse sentido, trabalhou associando à problematização textual imagens capturadas na Internet em sites de humor político (Charges) ${ }^{2}$. Ou seja, visto que toda aprendizagem se refere ao movimento do pensamento e ao direito de colocar problemas, a metodologia de redes de conversações toma como imprescindível investir na cartografia dos problemas que estão sendo engendrados no plano de imanência, associando a problematização das políticas educacionais do governo Bolsonaro 
pontuadas pela CNTE a charges de humor político, conjugando imagens a afetos/afecções produzidos pelos encontros dos corpos e buscando constituir o coletivo entre/nas redes de conversações.

As falas derivadas das conversações aparecerão entremeadas às argumentações/problematizações estabelecidas no desenvolvimento do texto. As conversas disparadas com as charges foram gravadas e transcritas. Ao longo do texto, elas aparecerão em itálico e com espaço simples, sem nenhum tipo de identificação ou diferenciação dos participantes. Em todos os momentos, as conversas ocorreram em múltiplas vozes, típico de um trabalho em sala de aula. É também preciso destacar que optamos por não recuar as cenas ou reduzir a fonte ao apresentarmos as conversas, de modo a dar maior visibilidade a seu texto, apostando eticamente em sua possibilidade de leitura em importância consoante ao texto acadêmico.

\section{O conservadorismo}

Segundo Bonazzi (1986), o termo conservadorismo é carregado de sentidos, o que dificulta bastante a sua compreensão. Tomado como substantivo, conservadorismo implica um conceito político, filosófico-sociológico. Como adjetivo, qualifica atitudes, ideias e valores. Daí o uso mais corrente do adjetivo conservador, apesar de não se configurar, tal qual o substantivo, numa definição autônoma e unitária, apresentando dificuldades na determinação de sua natureza e seus fins.

Com isso, a polissemia da palavra entra no cotidiano de forma variada, ganhando vida e sendo apropriada, muitas vezes, somente de modo pejorativo, classificando pessoas e coletivos, visto que uma pessoa pode ser politicamente inovadora e ter condutas conservadoras com relação à família.

Assim, uma primeira conclusão em relação ao tema é que ele é entorpecido por uma carga emotiva muito grande, já que se relaciona também com questões comportamentais. Se, pois, a Ciência Política realça no conservadorismo o caráter universal, fazendo dele uma constante necessária da política, perde de vista a especificidade do termo.

Entretanto, para a Ciência Política, de modo geral, o termo conservadorismo designa ideias e atitudes que visam à manutenção do sistema político existente e de seus modos de funcionamento, apresentando-se como contraposição das forças inovadoras e/ou progressistas. Essa forma de compreensão reduz as práticas conservadoras à existência de práticas progressistas. Ou seja, só seria possível entender o conservadorismo a partir das práticas opostas, dando, assim, um caráter individualista e reativo ao termo em destaque.

Para Bonazzi (1986), a tese acima induz uma interpretação de que o conservadorismo é sempre reativo, não sendo possível conceber um conservadorismo não reativo, pois, há séculos, existem no campo político os partidos conservadores, com propostas e agendas bem desenvolvidas. E esses são proativos, principalmente no que se refere ao desenvolvimento econômico e tecnológico. Porém, na perspectiva assumida neste artigo, 
o conservadorismo é entendido em sentido diferente da perspectiva de Bonazzi (1986), visto que designa um conjunto de forças que deseja e luta pela manutenção dos interesses do colonialismo capitalístico do ponto de vista econômico-político e defende uma moral burguesa em processos de identificação com um modelo patriarcal, deslocado dos espaços diferenciais de existência biológica e social.

Pela modelagem da existência e por padrões normativos, os conservadores parecem ou desejam ignorar que espaços produzem corpos e corpos produzem “endereço”, pois são forças ativas, apesar de muitas vezes essas mesmas forças atuarem de forma passiva.

Porém, segundo Rolnik (2016), tanto as forças macropolíticas como as forças micropolíticas podem ser tanto progressistas como reativas e conservadoras. Ressalta, porém, que as forças “colonial-capitalísticas” que têm sido alçadas ou tomado o poder são macropoliticamente reacionárias e micropoliticamente reativas e conservadoras. Entretanto, é precisamente a gravidade dessa experiência que leva Rolnik a nos alertar que não basta atuar macropoliticamente, porque, por mais que se faça no plano macropolítico, por mais brilhante que sejam as ideias e as estratégias, do ponto de vista micropolítico reativo, o que se consegue é uma reacomodação do mapa vigente, na melhor das hipóteses, com um grau de desigualdade um pouco menor. E tudo volta para o mesmo lugar, visto que o que tende a funcionar, segundo uma micropolítica reativa, é a desconexão da experiência do fora-do-sujeito, reduzindo-se, assim, à uma postura individualista.

Ou seja, no campo macropolítico e também no micropolítico, os corpos agem tanto de modo individual como coletivo, assim como de modo reativo ou ativo. Isso implica dizer que corpos e espaços se produzem como terminais de forças em relações de poder, ou seja, inseridos na possibilidade de serem forças ativas e passivas - são, portanto, fatos políticos. Toda produção de corpos dispara uma relação política e eles podem se constituir como forças ativas ou passivas (Guattari, 1986).

A macropolítica diz respeito às formas instituídas que governam, no caso, as proposições educacionais, a micropolítica opera em outra dimensão, contêm forças com outros fluxos e conexões, componentes micropolíticos que atravessam, transversalizam a macropolítica. "Em suma, tudo é político, mas toda política é ao mesmo tempo macropolítica e micropolítica” (Deleuze; Guattari, 1996, p. 83).

Para Rolnik (2016), existem dois tipos de experiência que fazemos no mundo. A primeira é a experiência imediata, baseada na percepção que nos permite apreender as formas do mundo em seus contornos atuais - uma apreensão estruturada segundo a cartografia cultural vigente. Em outras palavras, quando vejo, escuto ou toco algo, minha experiência já vem associada ao repertório de representações que disponho e que, projetado sobre esse algo, atribui-lhe um sentido. Esse modo de experiência é indispensável para a existência em sociedade, porém essa é apenas uma dentre as múltiplas experiências que a subjetividade faz do mundo e que operam simultaneamente. Trata-se da experiência individual, o que chamamos "sujeito".

O outro tipo de experiência que Rolnik apresenta é a subjetividade que faz de seu entorno uma experiência das forças que agitam o mundo como corpo vivo e que produzem 
efeitos em nosso corpo em sua condição de vivente. Tais efeitos consistem em outra maneira de ver e de sentir aquilo que acontece em cada momento. Aqui já não se trata da experiência de um indivíduo, pois o mundo “vive” em nosso corpo e resiste de modo ativo à sujeição capitalística. Esse mundo, que "vive” em nosso corpo coletivo, irrompe com força no processo de enunciação estabelecido na pesquisa entre imagens e conversações.

Então, por não alcançar a experiência do fora-do-sujeito - na qual nos compomos dos efeitos do mundo em nosso corpo, e são esses efeitos que nos indicam o que deve ser criado para que a vida coletiva volte a fluir - a experiência subjetiva é vivida e entendida como sendo do âmbito do indivíduo, movida por interesses individualistas (Rolnik, 2016).

A problematização dessa perspectiva individualista aparece nas conversações estabelecidas na/com a visualização da charge abaixo:

\section{NIVEL DE MOTIVAÇÃO PARA IR PROTESTAR NAS RUAS!}

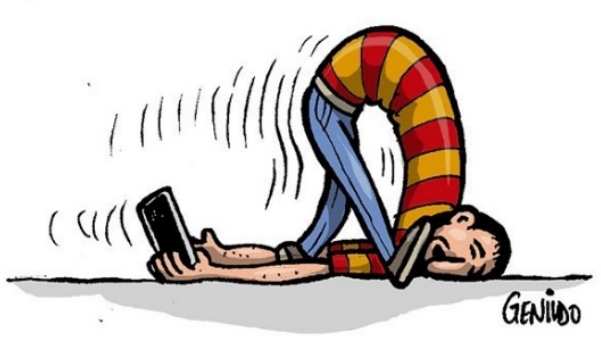

Genildo Ronchi, 25 julho 2019.

_ Eu acho brasileiro muito individualista. Tipo "Está bom pra mim, então deixa como está". Ou, então, "O buraco está quadrado, vamos ficar quadrados. O buraco está redondo, vamos ficar redondos”. Isso é uma questão política, mas é também cultural.

_ Quando a gente para e pensa o que está acontecendo na educação, na saúde pública, na previdência, quantas pessoas foram nessa manifestação?

_ Quais são as ações que os professores podem tomar dentro das salas de aula para mudar isso? Então, eu não ouço falar muito nessas ações. Eu vejo muito falar em político tal, político tal. Beleza! Mas, e nós? O que a gente tem força pra mudar? Qual a nossa posição diante disso?

_ Eu tenho muita dúvida sobre o que posso fazer em sala de aula e fora dela para mudar isso. 
As conversas acima enunciadas acenam para uma perspectiva de busca de superação de individualidade e da passividade, embora ainda em modos bastante reativos característicos tanto da macropolítica como da micropolítica dominante, ou seja, a micropolítica reativa do "inconsciente colonial-capitalístico" (Rolnik, 2016) que comanda o sujeito moderno, pois referida a um tipo de resistência egoísta e centrada na luta pela sobrevivência, para caminharmos para uma micropolítica ativa de resistência (molecular).

A micropolítica trata do campo das forças, do que é invisível, enquanto a macropolítica trata das formas, do que é visível. É justamente pelo fato de que esses modos são inseparáveis, que nos interessa a análise micropolítica, porque a educação e, especificamente, os cotidianos escolares costumam olhar somente para as formas, reduzindo o espaço à forma, como se nele apenas encontrássemos macropolítica.

A partir da ideia de que tudo é engendrado em uma relação de força, Deleuze e Guattari (1996) propõem uma micropolítica que devolva ao campo político cada ação, cada ato de produção de realidade. Esses atos nunca são fatos isolados, não são apenas formas, mas sempre estão engendrados em uma relação de poder, em uma relação de força. A micropolítica é um modo de recortar a realidade a partir do campo das forças, na medida em que essas forças também produzem realidades, afetos, desejos. A micropolítica nos permite analisar cada saber, cada corpo, cada endereço, cada objeto sob uma perspectiva de produção de realidade a partir das relações de poder.

Portanto, a subjetividade, para Guattari e Rolnik (1986, p. 32), “[...] não se situa no plano individual, seu campo é de todos os processos de produção social e material”. Sendo assim, o termo subjetividade não significa a definição de sujeitos a partir de algo interior a eles, como um plano individual, pois os indivíduos são como terminais dessa subjetividade exterior, dessas relações de forças, como toda produção social e material. Corpos também inibem ou induzem ações e, portanto, podem se constituir tanto de modo individualista como, compondo com outros corpos, de modo coletivo.

Assim, quando do debate desses assuntos no campo político, os conservadores estariam sempre contrários às minorias. Temas como direitos sexuais e reprodutivos, descriminalização das drogas, educação sexual estão sempre na mira dos discursos e da retórica dos conservadores.

Segundo Foucault (2006), o discurso vive por meio de si mesmo, tem autonomia e normas próprias. O discurso compõe o mundo e os sujeitos, colocando-nos em regimes discursivos que nos moldam a uma maneira de compreender, narrar e pensar como sujeitos no mundo. Por isso, quando interrogam os termos, mas, sobretudo, quando pensam os discursos sobre sexualidade, gênero, descriminalização das drogas e dos direitos reprodutivos, neutralidade na educação, dentre outros que circulam socialmente, os indivíduos e as populações os utilizam como dispositivos que levam à produção de regimes de verdade (Foucault, 2006).

O discurso não está situado fora dos dispositivos e práticas nos quais ele se corporifica e se produz, pois somos sujeitos constituídos pelo discurso, pelas normas e regras que se formam e pelas ferramentas que ele nos proporciona para a composição de 
nossa maneira de pensar e de agir no mundo, com o outro e conosco. Sendo assim, os discursos são sempre regidos por certas normas e valores que os levam a pensar o mundo sobre uma determinada ótica e influenciam suas práticas.

Dessa forma, também os discursos conservadores podem ser vistos funcionando como regimes de verdade, exclusão e repressão.

Entendemos, portanto, que há nos discursos conservadores, por sua intencionalidade de manutenção do status quo, um aparato de controle que impede que qualquer pessoa, em qualquer lugar ou circunstância, possa dizer tudo sobre determinado assunto. A charge e as conversações suscitadas, dispostas a seguir, exemplificam como se processam essas interdições:

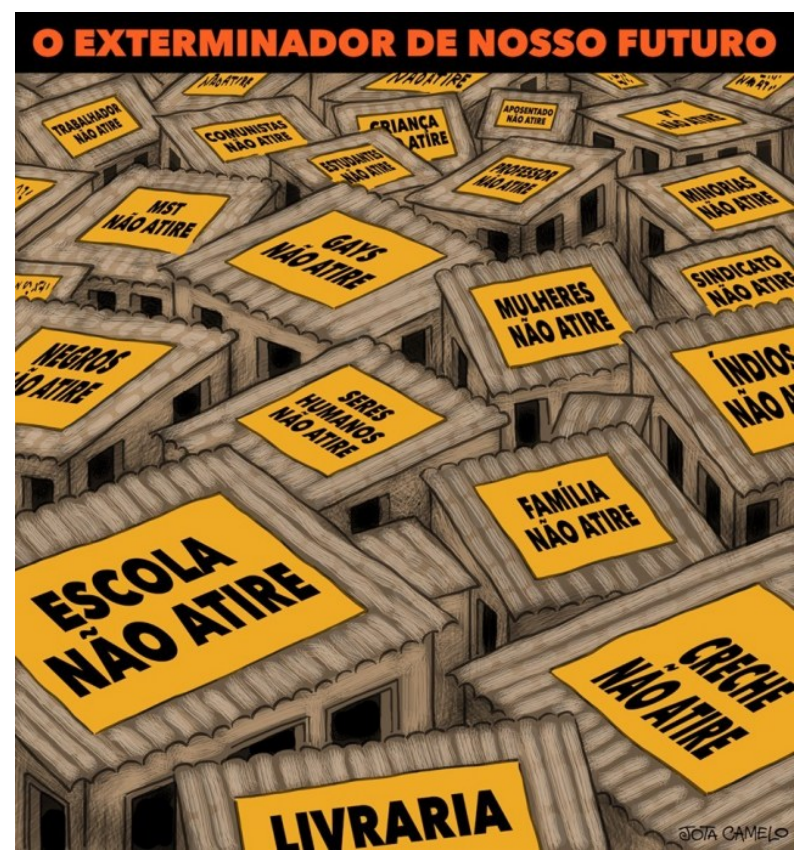

Jota Camilo, 13 maio 2019.

_ Eu acho que temos poucas aulas sobre política aqui. Lá, na escola, por exemplo, quando conversamos sobre política, muitos dizem coisas que não têm nada a ver. Nós, que deveríamos estar atualizados, não estamos. Eu acho que temos pouco acesso à política, porque o que eu sei é porque fui pesquisar, e olha que ainda não sei muita coisa. Precisamos ter desconfiança do que é publicado nos jornais.

- A aula de História vai falar sobre os antigos para pensarmos o presente. Precisamos ter aula de atualidades, de questões atuais que abordem os direitos humanos e a educação.

_ Verdade, questões atuais, mas tudo que se fala da atualidade é vigiado ou por colegas ou por alunos. 
Discordando da oposição pensamento conservador versus progressista, pois ambas discursividades se apresentam de modo reativo e ativo, importa analisar que, para os conservadores, no contexto do Brasil atual, o discurso e o pensamento político deles, seja no âmbito da macro ou micropolítica, é o que é considerado como verdadeiro. Vale reforçar aqui que o próprio discurso é elemento de disputa. O conservadorismo é um discurso, carregado de senso comum, o que o torna extremamente sedutor. Como bem analisa Mannheim (1959), o conservadorismo nasce do tradicionalismo, portanto tem um forte significado social e identitário, o que torna mais fácil para uma parcela da população se identificar com esse discurso. Nesse sentido, é bom destacar que os dispositivos de verdade não são exclusivos do pensamento conservador, pois essas disputas se dão em todos os campos sociais e são objeto de interesse especial para a área da educação, já que as demandas dos diferentes grupos estão encontrando respaldo no campo micropolítico, exigindo uma macropolítica educacional adequada às suas conquistas.

Um exemplo disso é a Lei $n^{\circ}$ 10.639/2003, que altera a Lei de Diretrizes e Bases de 1996, tornando obrigatório o ensino de história e cultura afro-brasileira. Nesse caso, as disputas do campo político se materializaram de forma objetiva em uma lei que, apesar de não resolver o problema, uma vez que a maioria das escolas ainda não a cumpriu, cria condições objetivas de luta. Todavia, muitas demandas ainda estão em fase preliminar de disputa. Esse é o caso das comunidades homoafetivas, que recentemente conquistaram, no Supremo Tribunal Federal (STF), a criminalização da homofobia, ou seja, o direito, tal qual o racismo, de ser considerado crime a ofensa contra a comunidade LGBTIS. Isso não significa que, no campo da vida cotidiana, tantos negros como homossexuais não continuem sofrendo variadas formas de discriminação.

De modo geral, os enunciados discursivos dos licenciandos se colocaram ao encontro das demandas das "minorias", embora não tenham fugido totalmente aos enunciados clichês que envolvem a discursividade sobre racismo e homofobia

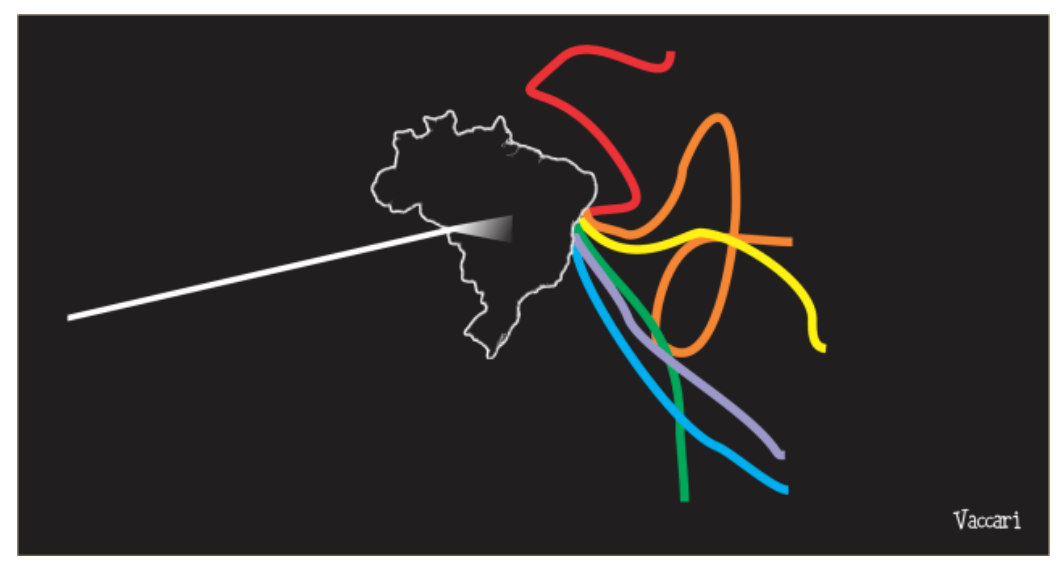

Marcio Vaccari, 27 junho 2019.

_ O Brasil é multicolorido, formado por diferentes pessoas, mas é mais colorido para determinada classe social. 
_ Acho que não só diferença de classe social, como de raça, gênero, sexualidade, e temos em nossas escolas esse mundo multicolorido, porém trabalhamos e somos trabalhados como estudantes de modo homogêneo, padronizado.

_ A educação é pública até certo ponto!

- Sobre a questão da educação pública, na verdade, não fizemos nada para a gente se apossar, tomar posse de nossas coisas. Igual a professora falou sobre o hospital, sobre lá, na Universidade, temos o planetário, galerias, pesquisas que saem para o mundo, e as pessoas não tomaram posse. Agora que o pessoal começa a lutar, quando vê que vai perder.

_É mais fácil falar mal, pegar casos isolados que aconteceram há anos, tipo "A Universidade não presta, porque só tem maconheiro!", "Naquele hospital, minha tia foi lá e não foi atendida, ele não presta!”. Você exclui por um olhar parcial.

_. Agora essas coisas estão muito mais visíveis, porque já está explícito o corte de verbas para as IES públicas e o interesse na privatização do ensino.

Assim sendo, cabe destacar que a política deve ser entendida como um modo de atividade humana que coloca sujeitos em relação, articulando-os entre si, segundo padrões e normas não necessariamente jurídicos ou relacionados com um marco legalinstitucional. Isso porque a política se faz, também, e de forma intensa, por microrrelações, como nos apontaram a micropolítica de Deleuze e Guattari (1996) e a microfísica do poder de Foucault (1979).

\section{Práticas discursivas conservadoras em educação no Brasil atual}

Apesar de considerar o conservadorismo, como sempre, somente reativo, a abordagem deste artigo não é a de opor, de modo contraditório, o conservador ao progressista, visto que pensamos e atuamos em fluxos das forças político-sociais que muitas vezes estão coengendradas.

Portanto, pensamos como Pelbart (2019), quando exemplifica, a partir do livro de Didi-Huberman (2011), a diferença entre a visão dos vaga-lumes ("lucciolas”) na obra de Dante Alighieri “A divina comédia” e na obra de Pasolini. No primeiro caso, na descrição do inferno, onde estão os pérfidos políticos florentinos, os vaga-lumes volteiam com luminosidade fraca, efêmera, como almas errantes, de modo que cada lume um pecador nas trevas guardava. No segundo caso, os vaga-lumes errantes apresentam uma conotação positiva, contrária, portanto, àquela visão de Dante, já não vinculada ao castigo, porém bastante próxima do amor, associando os vaga-lumes não só à inocência, à alegria e ao erotismo, mas também à arte e à invenção.

Essas forças coengrendadas não são, entretanto, do ponto de vista ético, da mesma dimensão, pois, para além de qualquer oposição simplista binária, necessitamos de processos problematizadores ao status quo dominante próprio do neoliberalismo e do 
capitalismo maquínico que, partindo de modelos/moldes discursivos, pretensamente com base em fundamentos universais, defende a posse de uma verdade e de uma educação voltada para os interesses do mercado e do poder concretizados/apresentados em pautas conservadoras.

Contudo, vivenciamos uma situação de avanço do conservadorismo com a ascensão política à Presidência da República de Jair Bolsonaro, de perfil extremamente autoritário e assumidamente antipopular, contrário aos direitos sociais duramente conquistados pelos segmentos historicamente oprimidos - mulheres, população LGBTI, população negra. Essa situação se agrava com o aumento do desemprego, da violência urbana, da desigualdade social, dos cortes de verba para as Universidades e Institutos Federais da Educação etc. Desse modo, o crescimento do pensamento conservador só pode ser compreendido mediante uma análise das mudanças na realidade sociopolítico-econômica que vivemos e, por conseguinte, na educação.

Dessa forma, podemos dizer que educação e, nela, a escola, foi o setor social com a maior capacidade de absorção das pautas dos segmentos mais marginalizados e oprimidos da sociedade. Por mais que os direitos conquistados estejam aquém do esperado, eles são relevantes, se considerarmos a realidade extremamente sofrida desses setores da sociedade, visto que, em um país conservador, cujos limites das lutas sociais são estreitos, a tendência é gerar uma grande ofensiva reacionária, principalmente em uma conjuntura de crise.

Assim, apesar dos limites estreitos das lutas sociais no Brasil da atualidade, as conversações estabelecidas pelos licenciandos sugerem o reconhecimento da perda dos direitos sociais, em especial os relativos à educação pública e, desse modo, problematizaram os cortes de recursos para a educação:

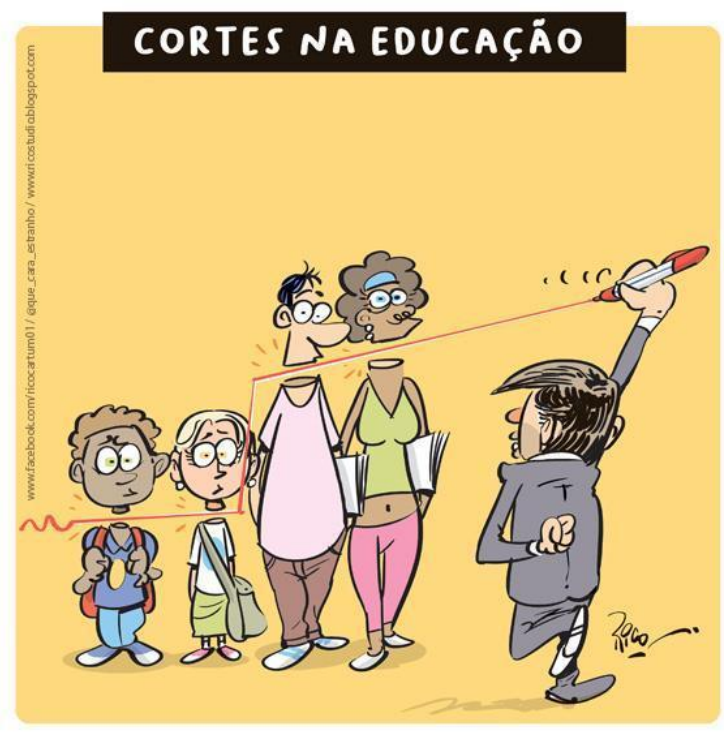

Rico Studio, 11 maio 2019. 
_ Sabe aquela coisa de que nada é tão ruim que não possa piorar? Então, parece que isso está acontecendo.

_ Eu vi um cara fantástico que dizia que ele queria saber o que se passa na cabeça das pessoas que dizem que o PT destruiu o Brasil em 13 anos, mas esquece o restante da história do país. E ele dizia que queria entender como conseguem destruir um país em 13 anos de governo.

_ Qual a lógica de achar que 13 anos de governo do PT condenaram o Brasil e não achar que 300 anos de escravidão não deixaram marcas até hoje?

_ A gente nega nossa história. Inclusive nosso querido presidente deu uma entrevista falando que não existe racismo no Brasil. Tem gente que insiste em negar que a ditadura aconteceu no país, que matou muita gente.

_ Os cortes em educação já estão em prática. Hoje, na escola onde faço estágio, a merenda foi feijão com ovo. Eu perguntei se só tinha isso e a tia da merenda disse que a comida não está chegando e elas estão "se virando nos 30 ”. E aí elas fizeram um tutu de feijão e cozinharam ovos, foi isso.

_ A questão é que as minorias que, na verdade, são a maioria, como pobres, mulheres, negros etc., estão cada vez mais desconsideradas.

Entretanto, na medida em que os licenciandos não pontuam a necessidade de composição política para uma vida coletiva gestada em modos ativos de contraposição ao “ideário colonial-capitalista” (Rolnik, 2016) e nem apresentarem enunciados propositivos, isso ajuda com que os grupos mais conservadores venham a ganhar mais influência nos debates, buscando uma intervenção direta no processo educacional. Processo que possui grande capilaridade em setores sociais com afinidade ao ideário conservador, em virtude de elementos como: o medo da violência social; o irracionalismo do fundamentalismo religioso como resposta às questões colocadas pela realidade; a falta de esperança em virtude do aumento do desemprego e da ausência de investimentos sociais do governo; além da própria difusão das ideias conservadoras e organização da sociedade de maneira a fomentar o individualismo descolado de quaisquer laços coletivos e sociais.

Assim, a “crise educacional” de uma sociedade em crise passa pelas mesmas justificativas do ideário dos setores conservadores e ligados ao capital: a presença da esquerda que busca impor sua forma de pensar aos alunos, doutrinando-os, em vez de ensinar os conteúdos das disciplinas; a estabilidade do servidor público, em especial do professor, que gera uma acomodação; a quantidade de greves que, independentemente de sua motivação, acabam por atrapalhar o processo educativo. Enfim, os culpados pelo fracasso do sistema educacional se tornam os professores, quando impõem para os sujeitos os seus valores, o que inclui a famigerada “ideologia de gênero”, responsável por destruir a família tradicional e, consequentemente, desestabilizar a sociedade brasileira (Castro, 2019).

Além disso, ao não garantir os investimentos públicos, o governo promove um sucateamento da estrutura pública, precarizando os mais diversos serviços, jogando a 
população contra o funcionalismo público e engendrando condições subjetivas para promover a privatização da educação em todos os níveis e graus.

Outro elemento relevante foi o estabelecimento da Base Nacional Comum Curricular (BNCC, 2018), atingindo a educação infantil, passando pelo ensino fundamental e culminando na reforma do ensino médio, cujo mote foi a flexibilização do ensino, a superação de um caráter “conteudista” para a preparação e autonomia do educando. Entretanto, é uma proposta deveras complicada, pois, com objetivos específicos, definidos em competências por quatro grandes áreas do conhecimento (Linguagens, Matemática, Ciências da Natureza e Ciências Humanas), a complementação, via itinerários formativos que não possuem obrigação de serem ofertados em sua totalidade pelas escolas, a retirada das disciplinas Filosofia e Sociologia e o recrutamento de docentes via notório saber fazem com que a escola se torne ainda mais fragmentária, aprofundando o caráter seletivo do processo educacional, tal como expresso na charge e nas conversações a seguir:

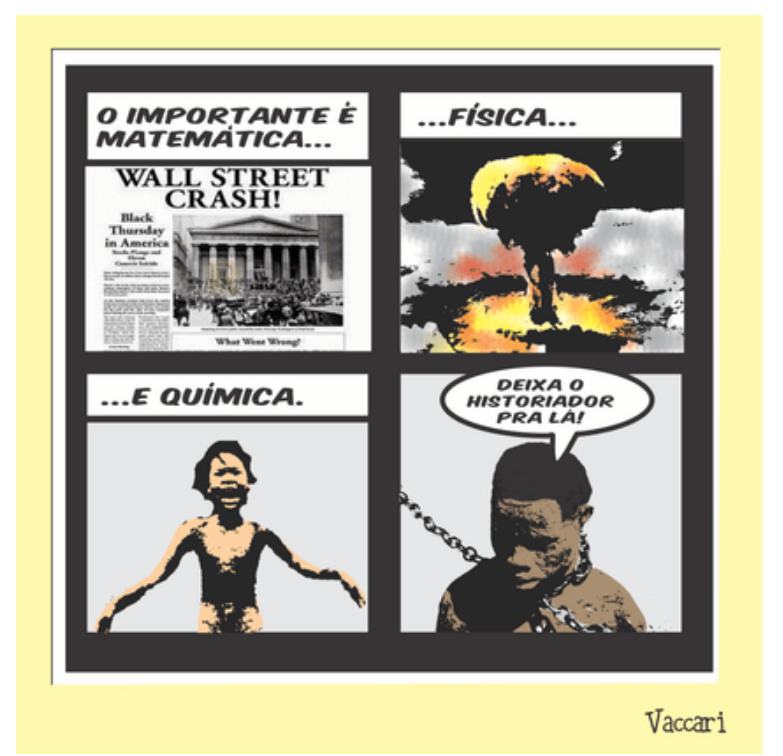

Marcio Vaccari, 10 maio 2019.

_ Isso me lembra muito sobre os cortes para Sociologia e Filosofia, porque sempre foi assim. Quando se tem que perder, perde no que mais possibilita o pensamento crítico, que é a Sociologia e a Filosofia, porque são disciplinas que nos fazem questionar a política, a sociedade, o eu, os modos de ser e estar no mundo. Então, todas as aulas devem ser assim, regadas por questionamentos e críticas.

_ No ensino médio, a gente fez um trabalho... Nas aulas de Filosofia fazíamos rodas de conversas sobre temas atuais. Fizemos uma feira filosófica em que cada sala tinha um tema, por exemplo: sala de tortura, sobre violência contra 
a mulher etc. Mas é sempre assim. Quando começam essas disputas políticas, eles querem tirar a Filosofia e a Sociologia.

- Pedagogia, também, não é um curso considerado. O curso de exatas é que é maravilhoso.

_ Eu queria falar sobre a formulação do pensamento crítico, que a Sociologia e a Filosofia proporcionam para a gente. Teve uma coisa que me deixou muito chocada, que é a questão dos "professores" com notório saber. Eu estou arrasada, porque eu vi ali a concretização da desvalorização do profissional que se capacita. Essa pessoa vai ganhar menos que um professor formado, mas vai ser mais rentável.

- Como vou ser professora sem querer que nossos alunos indaguem a nossa história? Ou como vou poder ensinar uma criança sem querer que ela pense? Porque, para mim, é praticamente impossível eu querer ensinar alguém, sem que essa pessoa possa exercer o pensamento crítico.

Para além da dimensão curricular - conteúdos, habilidades, competências desvinculada da preocupação com a formação do pensamento crítico, outro grande golpe conservador na educação é o projeto Escola sem Partido voltado contra a "contaminação ideológica de esquerda” nas escolas, movimento que data de 2004, mas que nunca obteve importância significativa nos debates educacionais, só assumindo relevância em 2014, quando acontece a primeira apresentação de um projeto de lei com o teor do Escola sem Partido, “[...] pelo deputado estadual Flávio Bolsonaro (PSC) na Assembleia Legislativa do Rio de Janeiro [...]. No mesmo ano, no município do Rio de Janeiro, o vereador Carlos Bolsonaro (PSC) apresentou projeto de lei com o mesmo teor do seu irmão, o deputado” (Cunha, s.d., p. 35).

Nesse aspecto, os segmentos de direita, vislumbrando os ganhos políticos com o eleitorado conservador, embarcam na onda do Escola sem Partido, o que faz com que o projeto assuma um grande vulto com apoio parlamentar. Foi apresentado em centenas de municípios, diversos estados e, também, no Senado e no Congresso. Isso se materializa no próprio site do Escola sem Partido, que possui uma aba específica para que se possa imprimir o projeto de lei (base), elaborado por Miguel Nagib, preparado para a apresentação nas mais diversas instâncias, demonstrando a grande organização e capilaridade do movimento (Castro, 2019).

No projeto de lei preparado para apresentação em nível federal, há o seguinte texto:

Art. $2^{\circ}$ - II: neutralidade política, ideológica e religiosa do Estado; [...] VIII: direito dos pais sobre a educação religiosa e moral dos seus filhos, assegurado pela Convenção Americana sobre Direitos Humanos; Art. $3^{\circ}$. O Poder Público não se imiscuirá na orientação sexual dos estudantes nem permitirá qualquer prática capaz de comprometer o desenvolvimento de sua personalidade em harmonia com a respectiva identidade biológica de sexo, sendo vedada, especialmente, a aplicação dos postulados da teoria ou ideologia de gênero; Art. $4^{\circ}$. No exercício de suas funções, o professor: I -não se aproveitará da audiência cativa dos alunos, para promover os seus próprios interesses, 
opiniões, concepções ou preferências ideológicas, religiosas, morais, políticas e partidárias; II - não favorecerá nem prejudicará ou constrangerá os alunos em razão de suas convicções políticas, ideológicas, morais ou religiosas, ou da falta delas; III - não fará propaganda político-partidária em sala de aula nem incitará seus alunos a participar de manifestações, atos públicos e passeatas; [...] V - respeitará o direito dos pais dos alunos a que seus filhos recebam a educação religiosa e moral que esteja de acordo com as suas próprias convicções (Escola sem Partido, s.d.).

A defesa de uma educação “neutra”, que era predominante até então, cede espaço à noção da primazia da família sobre a escola. A reivindicação é impedir que professoras e professores transmitam, em sala de aula, qualquer conteúdo que seja contrário aos valores prezados pelos pais. O foco principal é a “ideologia de gênero", mas a regra contempla também as posições políticas sobre outras questões e mesmo a teoria da evolução das espécies ou o heliocentrismo. Se as escolas privadas pudessem incluir cláusulas contratuais que garantissem a possibilidade de apresentação de determinados temas em sala de aula, as públicas teriam que se curvar aos vetos de tantos pais de alunos quantos quisessem se aproveitar da prerrogativa (Miguel, 2016, p. 601).

Nesse sentido, foi registrada a seguinte conversação associada indiretamente à observação da charge abaixo:

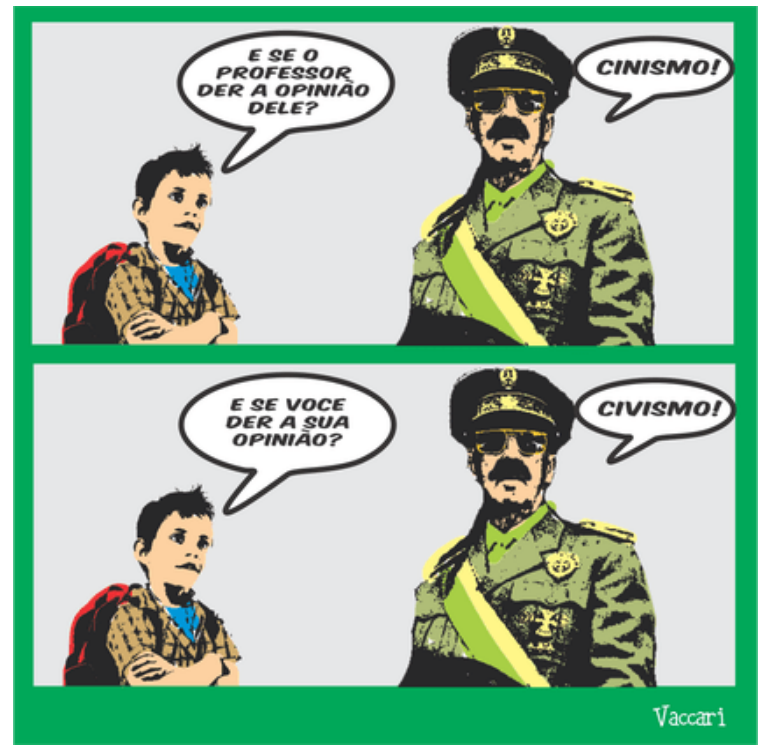

Marcio Vaccari, 22 junho 2019.

_ Ainda se discute pouco o que pode ser feito para mudar. Se fala muito mal sobre uma situação, se discute o problema, mas não se discute uma ideia.

_ É uma situação complicada. Hoje, por exemplo, você não pode fazer mais nada em sala de aula. A professora não foi gravada pelo aluno? Hoje, no 
Brasil, está muito difícil você conviver com as pessoas, que dirá você fazer uma política pública que agrade a todos.

_ É muito difícil. Você vai fazer alguma coisa, pronto! Então, hoje falta um pouco de união para você conseguir uma força de luta e resistência, para você mudar aquilo que você está reclamando. É preciso discutir a ideia, desfocar o problema. Problema tem... Essas rodas de conversa, essas manifestações precisam girar em torno de ideias, ir além de uma lista de reclamações.

A defesa de uma educação "neutra” encontra seu apogeu, entretanto, na proposição da Escola sem Partido que se converte, então, numa verdadeira cruzada com culpabilização dos professores pelos insucessos da educação pública, ignorando completamente as questões atinentes às condições de estudo e trabalho. $\mathrm{O}$ alvo do projeto e de seu fundador são os professores, acusados de doutrinar os seus alunos.

Além disso, o site do Escola sem Partido também conta com um espaço para a realização de denúncias de professores que doutrinam os seus alunos, para denúncias anônimas que nem exigem provas para que as denúncias sejam acatadas, instaurando-se um verdadeiro clima de desconfiança nos sujeitos envolvidos no processo educativo. $\mathrm{O}$ doutrinador é definido a partir de características que lhe são atribuídas: desvia-se frequentemente da matéria objeto da disciplina para discutir assuntos relacionados com o noticiário político ou internacional; adota ou indica livros, publicações e autores identificados com determinada corrente ideológica; alicia alunos para participar de manifestações, atos públicos, passeatas etc.; não só não esconde, como também divulga e faz propaganda de suas preferências e antipatias políticas e ideológicas; utiliza-se da função para propagar ideias e juízos de valor incompatíveis com os sentimentos morais e religiosos dos alunos, constrangendo-os por não partilharem dos mesmos pensamentos e juízos (Escola sem Partido, s.d.).

Promover a despolitização do espaço escolar é uma tentativa de evitar a qualquer custo que grande parte da classe trabalhadora que não tem acesso aos conteúdos próprios de seu interesse de classe, gênero, etnia etc., circunscritos apenas aos produtos ofertados pelos grandes conglomerados midiáticos, possa ter minimamente um espaço de reflexão e organização. "Despolitização refere-se à impossibilidade de as grandes massas trabalhadoras participarem dos principais direcionamentos e definições dos rumos acerca da política, economia e direitos sociais no país” (Gonçalves; Puccinelli, 2017, p. 77).

Assim, os movimentos reacionários na educação, especialmente o Escola sem Partido, têm como objetivo fundamental a criminalização e o cerceamento do trabalho docente, ou seja, é um projeto de classe muito bem definido, cujo objetivo central é a manutenção dos elementos ideológicos correspondentes à necessidade de acumulação do capital.

Esses elementos ideológicos transparecem nas conversações após a visualização das charges, como a necessidade de superação de um conservadorismo presente tanto na 
atuação como na formação dos professores. Nesse sentido, os licenciandos, de modo geral, se contrapõem aos clichês que transformam os docentes em réus.

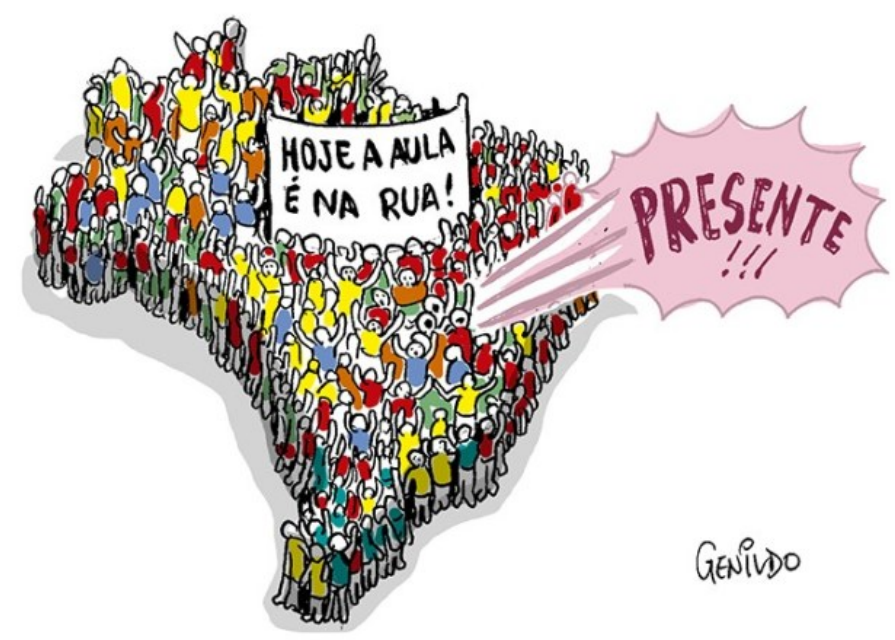

Genildo Ronchi, 30 de maio de 2019.

_Eu também acredito na valorização do magistério, mas não vejo a sociedade civil como os "não estudados". Não vou julgar dessa forma, mas eu vejo que existe a necessidade de valorização dos professores, mas para isso é preciso melhorar a sua formação.

_ Concordo! Você chega dentro de uma escola, você vê o mesmo formato de séculos atrás. Você vê os professores tentando ensinar do mesmo jeito, você vê uma educação que está sendo repetida, os erros estão sendo repetidos. Eu vejo muito isso. Não estou querendo condenar os professores, pois eu acho que é um conjunto de fatores que contribui, para, ao invés de se enxergar os professores como amigos, enxergar como inimigos.

_ Por trás disso entendo que tem todo um conjunto: políticas públicas, cultura, currículos especializados e hierárquicos, desvalorização da profissão, condições de trabalho, enfim, uma série de fatores que levam a isso, inclusive com destaque para o conservadorismo presente no ideário pedagógico.

Nesse sentido, os licenciandos discordam da posição de que à escola restaria apenas o papel de atuar em conformidade com os princípios e valores da ordem do capital. Qualquer mínima contradição de classes ou possibilidade crítica deve ser calada em virtude tanto da crise do capitalismo, o que implicaria uma redução dos espaços possíveis de questionamento da ordem pelo capital, quanto da própria condição de dependência, que faz com que a escola possua ainda mais limites para a sua atividade crítica. 
Todo esse processo persecutório e de criminalização dos docentes busca engendrar um novo princípio da realidade em que, envoltos pelo medo do constrangimento, da judicialização, inclusive da demissão, que resultaria na impossibilidade de garantir a sua sobrevivência, se consolide um estado de passividade diante das problemáticas sociais e das opressões mais corriqueiras. Constatamos, assim, a construção de um clima de vigilância permanente e desconfiança entre alunos, professores, suas famílias, mas também entre professores entre si, que passam, inclusive no âmbito escolar, a fiscalizar o trabalho de seus colegas (Castro, 2019).

Portanto, torna-se necessário sacudir os corpos de professores e estudantes como forças coletivas, visto que, como dissemos, parafraseando Rolnik (2016), tanto no campo macropolítico como no micropolítico, os corpos atuam de modo reativo ou ativo. O modo reativo significa professores com uma postura individual, o que resulta em acomodação ao colonialismo capitalístico, visto tratar-se de uma postura de dentro-do-sujeito, sem uma visão política mais ampla. O modo ativo, entretanto, pode ser suscitado pela mudança de perspectiva deflagrada por outra estética da experiência de educar e de se educar contra o conservadorismo, o que só é possível como acontecimento coletivo.

\section{Conclusão}

Nos limites deste artigo, concluimos com Negri e Hardt (2014) que "Isto não é um manifesto”, ou seja, não se coloca como um vislumbre para a superação do conservadorismo. Isso porque os atuais movimentos sociais inverteram a ordem, tornando obsoletas as profecias. Trata-se mais da tentativa de nos orientar na reinvenção dos modos de problematizar, nos cotidianos escolares, a experiência de educar em formas mais sensíveis usando, para tanto, uma estética da existência encharcada de vida afetiva e coletivo-política constituída em redes de imagens e conversações.

Nesse sentido, pudemos observar que, nas dobras das imagens, os licenciandos fizeram problematizações e quebraram alguns clichês, mas foram capturados por imagens- moral, já que as imagens, conforme Deleuze (1985), não somente se constituem como figuras, mas também as envolvem com um mundo que se mostrou, nesse caso, como o das aprendizagens, do coletivo e da escola.

Assim, na aposta aqui apresentada, a pretensão foi incomodar o pensamento dos licenciandos por meio de imagens de um mundo que os cerca. Violentar o pensamento usando imagens, com o intuito de esgarçar o “arco sensório-motor” (Deleuze, 1990) dos automatismos e dogmatismos, fazer denúncia e quebra de clichês de apoio ao conservadorismo, propondo, assim, uma estética da experiência de educar, mover-se em meio às imagens, visando a experimentar o jorro da vida em vias de diferenciação nas/das/com as redes de conversações. 


\section{Notas}

1. A escolha, como "sujeitos" da pesquisa, de licenciandos do Curso de Pedagogia, deveu-se ao fato de muitos deles já exercerem o magistério e/ou estágio na educação infantil e no ensino fundamental e todos já terem cursado o ensino médio e superior (vivência em todos os níveis e graus), assim como pela natureza do curso que demanda uma visão geral da educação brasileira e sua problemática do ponto de vista pedagógico e político-legalinstitucional.

2. Considerando a natureza e espaço de um artigo, apresentamos somente algumas charges utilizadas, capturadas no site www.humorpolítico.com.br, entre maio e julho de 2019, assim como selecionamos apenas algumas das falas emitidas durante as conversações.

\section{Referências}

BONAZZI, Tiziano Conservadorismo. In: BOBBIO, Norberto; MATTEUCCI, Nicola; PASQUINO, Gianfranco. Dicionário de política. Tradução de Carmem Varrialle, Gaetano Lo Mônaco, João Ferreira, Luís Guerreiro Pinto Cacais e Renzo Dini. Brasília: Editora Universidade de Brasília, 1986. p. 242-246.

BRASIL. Lei n ${ }^{\circ}$ 9.394, de 20 de dezembro de 1996. Estabelece as diretrizes e bases da educação nacional. Diário Oficial da União, Brasília, DF, 23 dez. 1996.

BRASIL. Lei $n^{\circ}$ 10.639, de 9 de janeiro de 2003. Estabelece no currículo oficial da Rede de Ensino, a obrigatoriedade da inclusão da temática “História e Cultura Afro-Brasileira”. Diário Oficial da União, Brasília, DF, 9 jan. 2003

BRASIL. Base Nacional Comum Curricular (BNCC). Brasília: MEC, 2018.

CONFEDERAÇÃO NACIONAL DOS TRABALHADORES EM EDUCAÇÃO (CNTE). Greve nacional dos trabalhadores em educação. Brasília/DF, 2019. Disponível em: http://www.cnte.org.br. Acesso em: 8 maio 2019.

CARVALHO, Janete Magalhães. Macro/micropolítica, cotidiano escolar e constituição de um corpo coletivo em devir. Educação Temática Digital, Campinas, v. 21, n. 1, p. 47-62, jan./abr. 2019.

CASTRO, Matheus Rufino. Capitalismo dependente, conservadorismo e educação: uma análise dos ataques reacionários à educação brasileira. Revista Trabalho Necessário, v.17, n. 33, p. 298-320, maio/ago. 2019.

CUNHA, Luiz Antônio. O projeto reacionário de educação. s.d. Disponível em: http://www.luizantoniocunha.pro.br/uploads/independente/1-EduReacionaria.pdf. Acesso em: 24 set. 2018.

DELEUZE, Gilles. A imagem-movimento. Tradução de Stella Senra. São Paulo: Brasiliense, 1985.

DELEUZE, Gilles. Diferença e repetição. Tradução de Luiz Orlandi e Roberto Machado. São Paulo: Graal, 1988.

DELEUZE, Gilles. A imagem-tempo. Tradução de Eloísa de Araújo Ribeiro. São Paulo: Brasiliense, 1990.

DELEUZE, Gilles; GUATTARI, Félix. Micropolítica e segmentaridade. Tradução de Suely Rolnik. In: DELEUZE, Gilles; GUATTARI, Félix. Mil platôs: capitalismo e esquizofrenia. Rio de Janeiro: Editora 34, 1996.

DIDI-HUBERMAN, Georges. A sobrevivência dos vaga-lumes. Tradução de Vera Casa Nova e Márcia Arbex. Belo Horizonte: Editora da UFMG, 2011.

DIDI-HUBERMAN, Georges. A imagem sobrevivente: história da arte e tempo dos fantasmas segundo Aby Warburg. Tradução de Vera Ribeiro. Rio de Janeiro: Contraponto, 2013. 
ESCOLA SEM PARTIDO (ESP). Anteprojeto de Lei Federal. Ementa: institui o Escola sem Partido. s.d. Disponível em: http://www.programaescolasempartido.org/pl-federal/. Acesso em: 15 jun. 2019.

ESCOLA SEM PARTIDO (ESP). Flagrando o doutrinador. s.d. Disponível em: http://escolasempartido.org/flagrando-o-doutrinador. Acesso em: 15 jun. 2019.

FOUCAULT, Michel. Microfísica do poder. Tradução de Roberto Machado. Rio de Janeiro: Graal, 1979.

FOUCAULT, Michel. A ordem do discurso. Tradução de Laura Fraga de Almeida Sampaio. São Paulo: Loyola, 1996.

FOUCAULT, Michel. Ditos e escritos: estratégia - poder e saber. Tradução de Elisa Monteiro. Rio de Janeiro: Forense, 2006. v. 4.

GONÇALVES, Leonardo Dorneles; PUCCINELLI, Vinícius Ramos. A reforma do Estado e o avanço neoconservador: impactos no caráter público da educação. Revista Pedagógica, v.19, n.42, p. 66-82, set./dez. 2017.

GUATTARI, Félix; ROLNIK, Suely. Micropolítica: cartografias do desejo. Petrópolis: Vozes, 1986.

MANNHEIM, Karl. O pensamento conservador. Tradução de Sylvia Lyra. Disponível em: $<$ https://pt.scribd.com/doc/307430017/Karl-Mannheim-O-Pensamento-Conservador>. Acesso em: 20 jun. 2019.

MIGUEL, Luis Felipe. Da “doutrinação marxista” à “ideologia de gênero”: Escola sem Partido e as leis da mordaça no parlamento brasileiro. Revista Direito e Práxis, Rio de Janeiro, v. 7, n. 15, p. 590-621, 2016.

NEGRI, Antonio; MICHAEL, Hardt. Declaração: isto não é um manifesto. Tradução de Carlos Szlak. São Paulo: n-1 Edições, 2014

PELBART, Peter Pál. Ensaios do assombro. São Paulo: n-1 Edições, 2019.

ROLNIK, Suely. A hora da micropolítica. São Paulo: n-1 Edições, 2016. (Série Pandemia).

SAMAIN, Etienne (org.). Como pensam as imagens. Campinas: Editora da Unicamp, 2012.

\section{Correspondência}

Janete Magalhães Carvalho: Doutora em educação pela Universidade Federal do Rio de Janeiro (UFRJ). Pós-Doutora em Currículos pela Universidade do Estado do Rio de Janeiro (UERJ) e em Sociologia da Vida Cotidiana pelo Instituto de Ciências Sociais da Universidade de Lisboa (ICS/UL/PT). Professora do Programa de Pós-Graduação em Educação da Universidade Federal do Espírito Santo (UFES). Coordenadora do Grupo de Pesquisa Com-Versações com a Filosofia da Diferença em Currículos e Formação de Professores. Pesquisadora 1D do CNPq.

E-mail: janetemc@terra.com.br

Texto publicado em Currículo sem Fronteiras com autorização da autora 